Portland State University

PDXScholar

Engineering and Technology Management

Faculty Publications and Presentations

2015

\title{
Comparing Technological Advancement of Hybrid Electric Vehicles (HEV) in Different Market Segments
}

Dong-Joon Lim

Portland State University

Shabnam Razeghian Jahromi

Portland State University

Timothy R. Anderson

Portland State University, tim.anderson@pdx.edu

Anca-Alexandra Tudori

Delft University of Technology

Follow this and additional works at: https://pdxscholar.library.pdx.edu/etm_fac

Part of the Engineering Commons

Let us know how access to this document benefits you.

\section{Citation Details}

Lim, Dong-Joon; Jahromi, Shabnam Razeghian; Anderson, Timothy R.; and Tudori, Anca-Alexandra, "Comparing Technological Advancement of Hybrid Electric Vehicles (HEV) in Different Market Segments" (2015). Engineering and Technology Management Faculty Publications and Presentations. 48.

https://pdxscholar.library.pdx.edu/etm_fac/48

This Post-Print is brought to you for free and open access. It has been accepted for inclusion in Engineering and Technology Management Faculty Publications and Presentations by an authorized administrator of PDXScholar. Please contact us if we can make this document more accessible: pdxscholar@pdx.edu. 


\title{
Comparing Technological Advancement of Hybrid Electric Vehicles (HEV) in Different Market Segments
}

\author{
Dong-Joon Lim ${ }^{\mathrm{a}}$, Shabnam R. Jahromi ${ }^{\mathrm{a}}$, Timothy R. Anderson ${ }^{\mathrm{a}}$, Anca-Alexandra Tudori ${ }^{\mathrm{b}}$ \\ ${ }^{a}$ Dept. of Engineering and Technology Management, Portland State University, Portland, USA \\ ${ }^{\mathrm{b}}$ Dept. of Policy Analysis, Delft University of Technology, Delft, Netherlands
}

\begin{abstract}
The Toyota Prius was first introduced in 1997 and since then over 150 hybrid electric vehicles (HEVs) have been brought to the automobile market around the world. This was spurred by a major interest in the future of vehicles using 'alternative fuel' for addressing environmental and fuel dependency concerns. Based upon previous work ${ }^{1}$, which identified an input-output model that could successfully explain the progress of HEV technologies, this study evaluates and compares the technological advancement observed in different HEV market segments over the past 15 years. The results indicate that the introduction of a wide range of midsize HEVs is posing a threat to the two-seaters and compact HEV segments while an SUV segment shows a fast adoption with a significant performance improvement. The rates of change for each segment are also provided to give insights into the estimation of the future performance levels for new product development target setting purposes.
\end{abstract}

Keywords: hybrid electric vehicle, technological forecasting, data envelopment analysis, market segment, rate of change.

\footnotetext{
${ }^{1}$ An early version of this study was presented at the Portland International Conference on the Management of Engineering and Technology (PICMET ’13) and published in the Proceedings [1].
} 


\section{Introduction}

Increasing fuel prices, government regulation, and a general desire to reduce environmental concerns have resulted in increased sales for fuel efficient vehicles. The Toyota Prius, introduced in 1997, was the first major hybrid electric vehicle (HEV) and since then most other manufacturers have introduced HEVs with varying success. While popular, the Prius and other vehicles were small and did not satisfy the needs of many other market segments. Over the following years, manufacturers developed HEVs to serve other segments.

Electric vehicles can be broadly categorized as 'pure-electric' (i.e. using only a battery and an electric motor for propulsion without tailpipe) or 'hybrid-electric' (i.e. combining the conventional internal combustion engine with an electric motor and battery). As the electric vehicle market grows, related technologies are progressing every year especially in terms of driving range and fuel economy. In particular, the anxiety on the travel range of pure electric vehicles has been reduced by the advent of HEV. Besides, the fuel economy of the HEV has been greatly improved in plug-in HEV that can be recharged from an external grid.

Jahromi et al. applied technology forecasting using data envelopment analysis (TFDEA) to the HEV industry in an attempt to build an accurate technological forecasting model [1]. Their work revisited the original study conducted by Tudorie [2] and identified the input and output parameters that can better explain the progress of HEV industry. Specifically, the original study selected two input parameters: weight of the vehicle and combined output power of electric motor and combustion engine. The output parameters were acceleration rate, $\mathrm{CO}_{2}$ emission and fuel economy. Those parameters were mostly selected based on the dynamics of combustion engine and electric motors. The dataset used in this study included a diverse set of vehicles, which required more comprehensive assessment to take multifaceted performance factors into 
account. Jahromi et al. later revised the model by incorporating additional parameters; Manufacturing Suggested Retail Price (MSRP) was selected as the only input and acceleration rate, fuel economy, a measure for miles per gallon equivalent, and seating capacity were selected for outputs. The revised model was able to explain the technological advancement with improved forecasting accuracy.

The current study further extends the previously developed model considering different market segments as well as applies it to the up-to-date HEVs so that technological advancement observed over the past 15 years can be investigated. Furthermore, the rates of change for each segment are provided to give insights into the estimation of the future performance levels for new product development target setting purposes.

\section{Research methodology}

As technology becomes sophisticated, there are few technologies that truly possess only a single technical capability. The rate of change also varies over time, being affected by the maturity levels of component technologies. This structural complexity makes today's technological forecasting even more challenging, which leads to the question: how to combine growth patterns of each attribute to describe the multi-objective technology systems?

To tackle this multi-attribute problem, modern technological forecasting studies frequently use frontier analysis methods. The idea is to construct the production possibility set from the best practice technologies using multiple inputs and outputs of the systems so that underperforming technologies are identified and compared against constructed frontier of the production possibility set. The evolution of the frontier surfaces is then monitored over time to capture the rate of change by which future technological possibilities can be estimated. This approach is 
particularly advantageous when the multiple tradeoffs between product characteristics exist and vary by manufacturer, by market segment, and over time [3,4].

To accommodate time-series application of frontier analysis into technological forecasting, Inman developed a measure to quantify the rate of frontier expansion by which the arrival of following technologies can be estimated [5]. Specifically, his method, TFDEA, establishes the state-of-the-art technology frontier using the data points identified as relatively efficient using DEA (see Fig. 1). Note that the frontier is a set of convex combinations formed by state-of-theart technologies hence it's not a curved surface but a piecewise linear combination. The tradeoffs between technical capabilities can be considered as a radial improvement within this frontier space. The TFDEA iterates the frontier formation process over time to track the rate of frontier shift. This momentum of progress is then used to make a forecast for the future technologies.



Figure 1 Two-dimensional illustration of TFDEA

TFDEA, being an extreme point frontier analysis technique, uses only the state of the art technologies to measure the technological advancement. In contrast, central tendency approaches 
such as regression are influenced by non-state-of-the-arts or mediocre technologies as well. Comparisons of TFDEA to central tendency approaches have shown its usefulness in a wide range of technological forecasting applications [6-10].

TFDEA also inherits the ability to identify technology segments in an objective manner from its non-parametric nature (see Fig. 2.) The piecewise linear facets represent different tradeoffs, i.e. technologies subject to corresponding facet may have a similar mix of input-output levels [11], which makes it possible to distinguish fast/slow advancing technology segments within the benchmarking process. Lim and Anderson's study showed that capturing local rates of change from identified frontier facets and utilizing them for individual forecasting targets improve the forecasting accuracy in general [12].

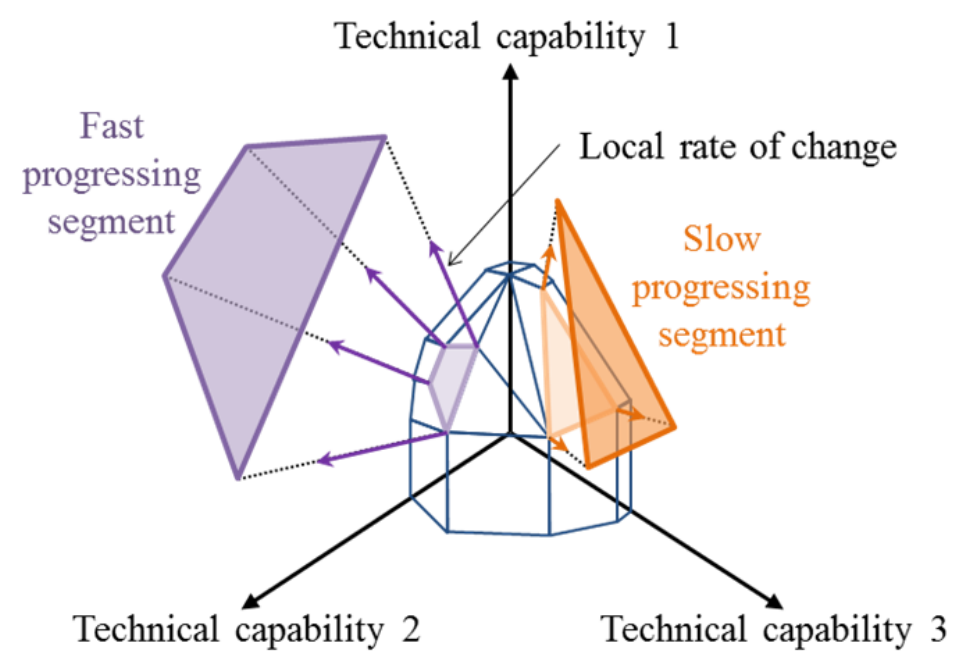

Figure 2 Illustration of segmented rate of change in TFDEA

Figure 3 shows the process of TFDEA in the envelopment model assuming variable returns to scale and dynamic frontier year with three separate stages. The first stage, shown by (1)-(9), iterates efficiency measurement in a time series manner so that the evolution of the state-of-the- 
art frontier can be monitored. The variable $\phi_{k}^{h \in\{R, C\}}$ represents the radial output efficiency of technology $k$ at the time of release $(R)$ and current frontier time $(C)$ in which the forecast is conducted. The variable, $\lambda_{j k}^{h}$, describes how much of technology $j$ is used in setting a target of performance for technology $k$. The objective function (1) also incorporates minimizing effective dates to ensure reproducible outcomes from possible alternate optimal solutions by distinguishing between Pareto-efficient technologies [13,14].

The frontier separation is imposed by (7) to deal with the external nondiscretionary factor, i.e. categorical variables [11]. This restricts the reference set for each technology being evaluated to technologies presenting only same or more disadvantageous conditions in terms of the categorical index $[15,16]$. Therefore, this requires the categorical variables to be arranged in a rank order according to the favorable condition. We introduce a categorical variable for the HEV application in the following section to account for the nondiscretionary factor.

The second stage calculates the rate of change, $\gamma_{k}^{C}$, by taking all technologies that were efficient at the time of release, $\phi_{k}^{R}=1$, but were superseded by new technologies at the current frontier time $C, \phi_{k}^{C}>1$. The local rate of change, $\delta_{j}^{C}$, can then be obtained by taking the weighted average of rates of change for each technology on the current state-of-the-art frontier [12].

The last stage makes a forecast of the arrival of future technologies. In (12), $t_{k}^{\text {forecast }}$ indicates the estimated time of arrival of future technology $k$ based on the individualized rate of change obtained by combining the local rate of change of state-of-the-art technology $j, \delta_{j}^{C}$, that constitutes the frontier facet onto which technology $k$ is being projected. 


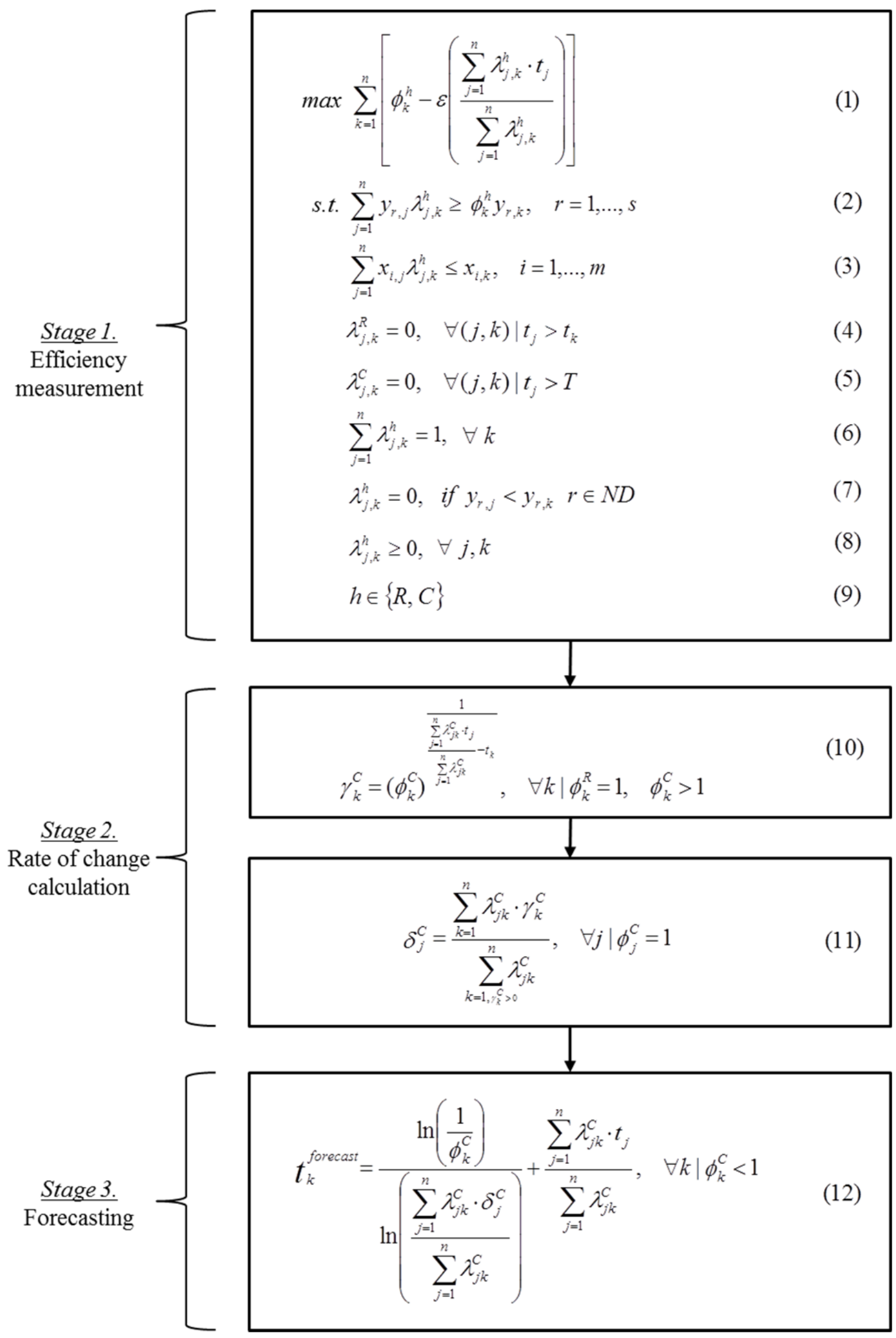

Figure 3 TFDEA process 


\section{Research model and dataset}

\subsection{TFDEA parameters}

\section{A. Input variable}

MSRP: Manufacturer's suggested retail price can be considered as a reasonable proxy for manufacturing cost due to a high presumed correlation. The vehicles in the dataset were from different countries and released in different years therefore the actual MSRP for each vehicle was converted into 2013 U.S. dollar value through the following steps:

1. The vehicle's MSRP in the year of release was found through the manufacturers' website or car review websites.

2. If the MSRP was in currency other than U.S. dollars, the value was converted to the equivalent amount in U.S. dollars using the exchange rate of the year of release. This study used the historical exchange rates provided by OANDA Corporation for the conversions [17]. Equation 13 shows the formula to convert the MSRPs in the original currency to U.S. dollar equivalent:

$$
M S R P_{U . S . \text { dollar equivalent }}=\text { Exchange rate }_{\text {year of release }} * M S R P_{\text {in original currency }}
$$

3. To inflate a past dollar value into present value, Equation 14 was used by applying the historical consumer price index (CPI) and the CPI of the year 2013. The CPI values were obtained from the Bureau of Labor Statistics and the formula can be found as below [18]:

$$
M S R P_{2013} \text { equivalent }=M S R P_{\text {year of release }} *(2013 \mathrm{CPI}) /(\text { Year of release } C P I)
$$

\section{B. Output variables}

Acceleration rate: This value determines the time (in seconds) it takes for a vehicle to go from 0 to $100 \mathrm{~km}$ (or 60 miles). Equation 15 shows the formula to calculate the acceleration rate: 


$$
\text { Accelaration rate }\left(\frac{\mathrm{km}}{\text { hour }} \text { per second }\right)=\frac{\text { speed range }\left(\frac{\mathrm{km}}{\mathrm{h}}\right)}{\operatorname{time}(\operatorname{second})}
$$

Fuel economy: Fuel economy shows the distance a vehicle can travel in one unit of fuel. The Environmental Protection Agency (EPA) provides information on fuel economy for the vehicles available in the U.S. market [19]. This study used the fuel economy value for combined city and highway driving cycles that was officially announced by the EPA.

Note that the fuel economy estimation is complicated in plug-in HEVs as they can drive in pure electric mode from having been charged with the grid. Therefore the fuel economy of plugin HEV was modified so that it takes account of hybrid mode only. To consider the additional dimension of plug-in HEV's performance, i.e. pure electric mode, another output of fuel economy is needed to be incorporated in the model as discussed below.

Max of MPG and MPG equivalent: The EPA developed a mile per gallon equivalent (MPGe) for plug-in HEVs to take all-electric range into account. This value is based on the gasolineequivalent energy of electricity [20]. Specifically, 1 gal of gasoline can be approximated to 33.7 kilowatt per hour of electric energy. For vehicles that were not introduced in the U.S. market, the value of MPGe was calculated using the Equation 16:

$$
\text { MPGequivalent }=\frac{33.7 * \text { drivingrange }}{\text { batterycapacity }}
$$

Since this parameter takes the maximum of MPG and MPGe, conventional HEVs have the same value as their fuel economy. Consequently, adding this parameter can address the additional feature of plug-in HEV without penalizing conventional hybrid cars in TFDEA model. 


\section{Categorical parameter}

Vehicle class: Unlike the earlier work by Jahromi et al. [1] that included seating capacity as one of the output parameters to take capacity of the vehicle into account, this study used vehicle class as a categorical parameter. This is because seating capacity is more of design characteristics suitably determined for the target market than performance characteristic that manufacturers want to increase. Furthermore, vehicle class can be used to classify the different types of vehicle more precisely than seating capacity. For example, Prius $\mathrm{C}$ is a compact vehicle and Prius V is a midsize vehicle while they have the same seating capacity of five.

The EPA defines vehicle classes based on interior passenger and cargo volumes as well as design purposes [19]. This study adopted the EPA's criteria and grouped HEVs into 7 classes: two-seaters (TS), compact (C), midsize (M), large (L), sport utility vehicle (SUV), minivan (MV), and pickup truck (PT). By using the above order of vehicle classes ${ }^{2}$ as categorical indices, HEVs can only be compared to HEVs in the same or following classes. For example, HEVs in the last class (i.e. pickup truck) are only compared with HEVs in the same class, but HEVs in category M are compared with HEVs in the same and/or following classes (i.e. M, L, SUV, MV, and PT) in terms of per price performances. Intuitively, the category M vehicle will not be compared against any vehicles from preceding classes (i.e. TS and C). Consequently, this enables to reflect a great deal of information contained in each HEV market segment that would be lost in any point-comparison without consideration on environmental factors [15].

\footnotetext{
${ }^{2}$ This should be understood as the order of difficulty to achieve per price performances due to structural requirements for each market segment rather than mere vehicle sizes. For example, while pickup trucks have a range of sizes, the industrial loads that need to be carried in pickup trucks may cause design demands beyond that of minivans that are typically reflected in lower fuel economy. Also, note that EPA only applies volume criteria for cars (TS, C, M, and L) and weight criteria for trucks (SUV, MV, and PT).
} 


\subsection{Dataset}

The dataset has been updated to cover total 154 HEVs including 11 plug-in HEVs from 1997 to 2013 (see Table1 for a summary and Appendix 1 for the full dataset.) The EPA database was the main source to collect the required information of technical attributes. Other sources were cross referenced especially for the vehicles released outside the U.S. and, in such a case, information was prioritized in order of technical report, product manual, benchmarking journals, and review sites.

Table 1 Dataset summary

\begin{tabular}{llrrrrrrr}
\hline Vehicle class & & $\begin{array}{l}\text { Two- } \\
\text { seaters }\end{array}$ & Compact & Midsize & Large & SUV & Minivan & $\begin{array}{l}\text { Pickup } \\
\text { truck }\end{array}$ \\
\hline \multicolumn{2}{l}{ Number of vehicles } & 9 & 32 & 56 & 8 & 37 & 4 & 8 \\
\hline \multicolumn{2}{l}{ First introduction (Years) } & 2000 & 1997 & 2004 & 2009 & 2004 & 2003 & 2004 \\
\hline MSRP & Max & $\$ 21,435$ & $\$ 49,650$ & $\$ 118,544$ & $\$ 104,300$ & $\$ 97,238$ & $\$ 38,085$ & $\$ 57,095$ \\
$(2013$ & Average & $\$ 19,521$ & $\$ 27,908$ & $\$ 37,335$ & $\$ 85,251$ & $\$ 47,495$ & $\$ 29,616$ & $\$ 39,819$ \\
equivalent) & Min & $\$ 18,936$ & $\$ 14,072$ & $\$ 11,849$ & $\$ 25,200$ & $\$ 17,045$ & $\$ 16,394$ & $\$ 30,090$ \\
\hline Acceleration & Max & 12.20 & 14.93 & 19.61 & 20.41 & 18.52 & 9.26 & 12.35 \\
(km/h/s) & Average & 9.99 & 9.84 & 12.63 & 15.97 & 12.99 & 7.85 & 11.12 \\
& Min & 9.24 & 7.04 & 7.14 & 12.35 & 8.33 & 6.29 & 9.09 \\
\hline MPG & Max & 60.69 & 68.21 & 72.92 & 43.00 & 33.64 & 58.80 & 22.35 \\
& Average & 50.08 & 43.54 & 35.82 & 26.06 & 26.22 & 49.28 & 19.89 \\
& Min & 37.00 & 28.00 & 20.00 & 21.00 & 18.82 & 40.46 & 17.00 \\
\hline Max of & Max & 60.69 & 98.00 & 100.00 & 43.00 & 38.00 & 58.80 & 22.35 \\
MPG and & Average & 50.08 & 50.95 & 41.42 & 26.06 & 26.45 & 49.28 & 19.89 \\
MPGe & Min & 37.00 & 28.00 & 20.00 & 21.00 & 18.82 & 40.46 & 17.00 \\
\hline
\end{tabular}




\section{Analysis of the technological advancement}

The model was implemented using the software ${ }^{3}$ developed by Lim and Anderson [21]. Figure 4 provides a sketch of what segment has been dominating the market in terms of technological superiority by showing how the state-of-the-art frontier of hybrid electric vehicles over time has been made up of vehicles from different segments. That is, the percentage indicates the amount of which each HEV segment stakes out the state-of-the-art frontier that any particular HEV is aiming for. In 1997 for example, the state-of-the-art frontier was constructed by a sole compact HEV, the $1^{\text {st }}$ generation of Prius, without a competition therefore the dark blue region (i.e. compact segment) filled up the entire frontier space. As other types of HEVs began to be released in the market over time, the state-of-the-art frontier has been made up of a wide variety HEVs.

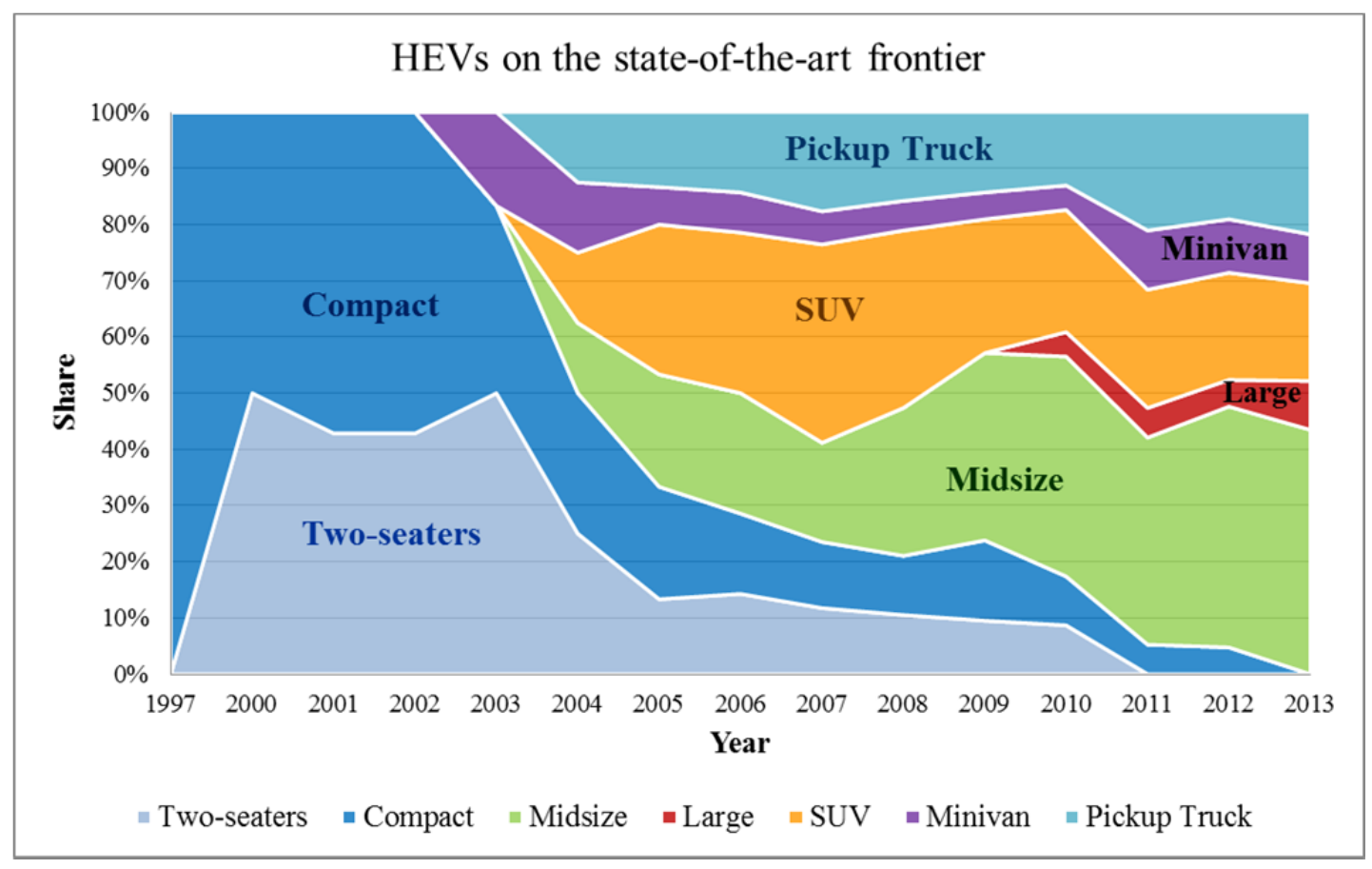

Figure 4 State-of-the-art HEV distribution

\footnotetext{
${ }^{3} \mathrm{R}$ package for a standard TFDEA is available at http://cran.r-project.org/web/packages/TFDEA/index.html A web-based version is also available at http://tfdea.com
} 


\subsection{Two-seaters and compact segments: "stagnated"}

Until 2003, all HEVs in our dataset were either two-seaters or compact automobiles. This resulted in these two segments dominating the HEV market but the introduction of vehicles in other segments resulted in an erosion of this dominance. Despite consecutive introductions of successful lineups such as Honda Insight and Toyota Prius C, the technological dominance has been shrinking as the other types of HEVs' market advance.

Note that there were no two-seaters or compact HEVs on the state-of-the-art frontier in 2013. This indicates that two-seaters and compact HEVs are no longer competitive with vehicles in other segments, though they presumably have a light weight advantage. This is particularly attributed to the encroachment of the midsize HEVs that is extending its target market with a fast technological advancement recently. One can verify this by the list of benchmarks of two-seaters and compact HEVs in 2013. Table 2 contains this information. The combination of benchmark and dominated set can be understood as a competitor group in terms of their product spec where the former is found to be outperforming the latter. For example, Prius ( $1^{\text {st }}$ generation), indicated as vehicle number of 1 , has become obsolete since its introduction in 1997 and it was superseded by its benchmarks: Accord Hybrid (21), Prius alpha (V) (80), and Fit Shuttle Hybrid (82).

Except for the Fit Shuttle Hybrid (82), benchmarks of all two-seaters and compact HEVs were found to be midsize HEVs. This suggests that midsize HEVs are outperforming HEVs from those two segments with similar technical characteristics. That is, midsize HEVs are penetrating the market niche that has been dominated by two-seaters and compact HEVs. In fact, the bar for energy efficiency is constantly being raised as more competitors including bigger vehicles have come into the market place with innovative features such as plug-in technology. Hence, high fuel economy is not entirely the domain of smaller vehicles any more [22]. This instigated makers of 
small HEVs to engage in more ingenious designs and development improvement (e.g. Toyota's new global architecture project) [23].

Table 1 Benchmarks of two-seaters and compact HEVs

\begin{tabular}{|c|c|c|}
\hline \multirow{2}{*}{$\begin{array}{l}\text { Benchmarks } \\
\text { (class) }\end{array}$} & \multicolumn{2}{|l|}{ Dominated set $^{*}$} \\
\hline & Two-seaters & Compact \\
\hline $21(\mathrm{M})$ & $4,6,7,9,12,18,55,90,136$ & $\begin{array}{l}1,3,5,10,16,19,43,47,63,66,71,77,78,79,88, \\
97,102,111,112,113,117,138,140,141\end{array}$ \\
\hline $40(\mathrm{M})$ & & 10 \\
\hline $56(\mathrm{M})$ & & 99 \\
\hline $67(\mathrm{M})$ & & $2,46,81$ \\
\hline $80(\mathrm{M})$ & $4,6,7,9,12,18,55,90,136$ & $\begin{array}{l}1,2,3,5,16,19,43,46,47,54,63,66,71,77,78, \\
79,81,88,97,102,111,112,113,117,138,140,141\end{array}$ \\
\hline $82(\mathrm{MV})$ & $4,6,7,9,12,18,55,90,136$ & $\begin{array}{l}1,3,5,10,16,19,43,47,63,66,77,88,97,102, \\
111,117\end{array}$ \\
\hline $145(\mathrm{M})$ & & $46,71,78,79,112,113,138,140,141$ \\
\hline $152(\mathrm{M})$ & & $68,99,154$ \\
\hline $153(\mathrm{M})$ & & 103 \\
\hline
\end{tabular}

${ }^{*}$ : List of HEVs who cited the corresponding state-of-the-art HEV as a benchmark

\subsection{Midsize segment: “flourishing”}

Continuing the previous discussion, it is noteworthy that midsize segment has shown a fast adoption rate with a superior technological performance recently. Indeed, hybrid technology has gained substantial popularity not only in fuel prices but also in reliability and longevity of powertrain that almost every auto manufacturers began to add hybrid version of their conventional midsize models to their brochures [24].

Figure 5 further explains the market penetration of midsize HEVs into the compact segment. Although the average price of midsize HEVs is still slightly higher than compact HEVs, not only the acceleration of midsize HEVs outperforms compact HEVs but also the gap of average fuel economy between compact and midsize HEVs is getting narrower. Especially, recent midsize 
plug-in HEVs such as Ford C-Max Energi (152) and Fusion Energi (153) have surpassed the fuel economy of any other compact HEVs as shown in the bottom right figure. This would attract customers who pine for a sportier vehicle in addition to roomier interior and safety features to the midsize segment with a variety of purchase options.
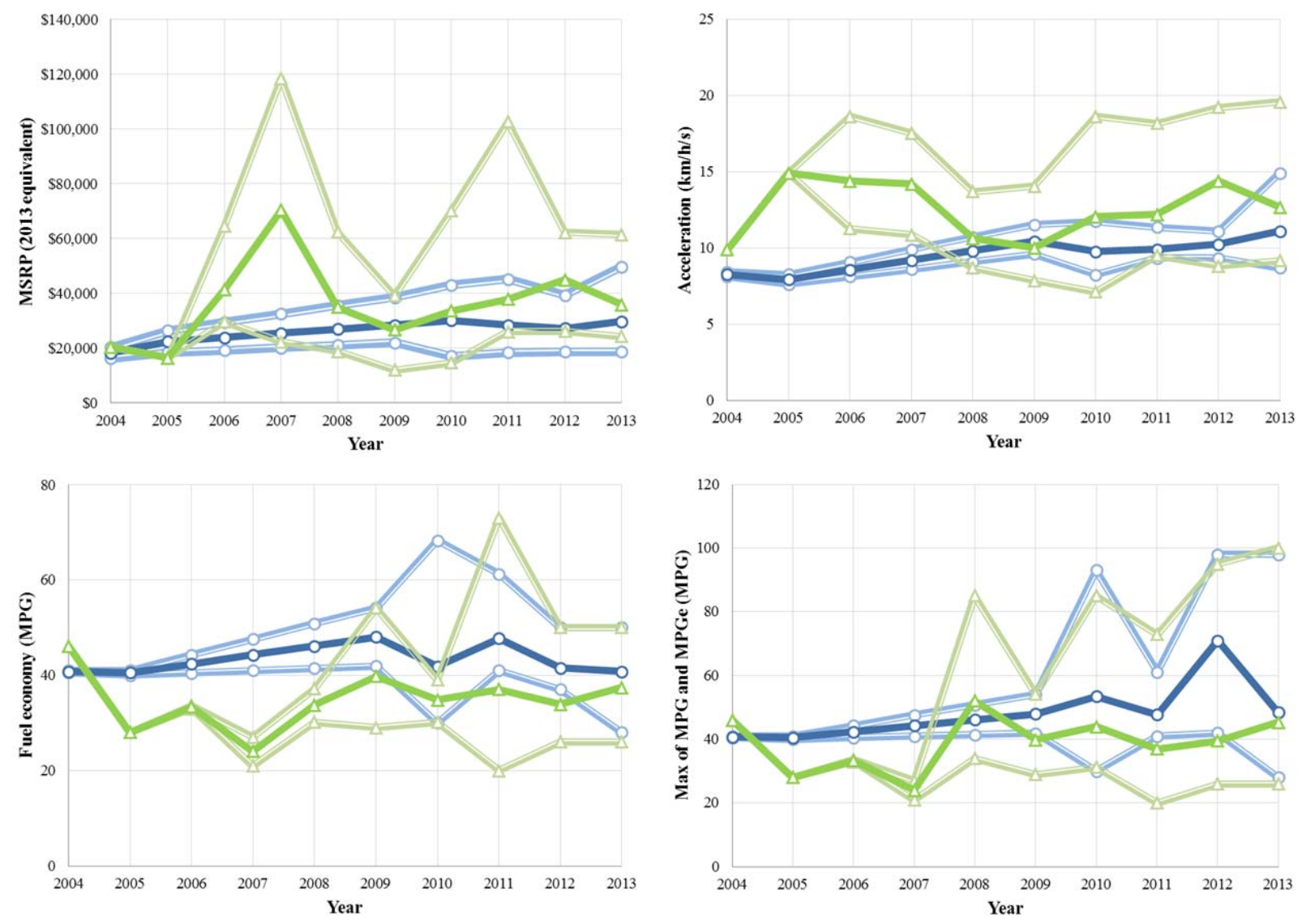

$=$ Compact (Max)

$\triangle=$ Midsize (Max) $\triangle$ Midsize (Average) $\quad=\triangle$ Midsize (Min)

Figure 5 Encroachment of midsize segment into the compact segment

Almost by definition, benchmarks (i.e. state-of-the-art HEVs) targeting a niche market won’t have a big dominated set who cited them as a benchmark [25]. In contrast, state-of-the-art HEVs with a broad scope must have been cited as a benchmark by many other competitors. 
Consequently, it would be possible to reveal whether an HEV on the 2013 state-of-the-art frontier is the niche or the broad player if the information on which and how many HEVs were compared with them was available. This has been done in Table 3. 
Table 3 Benchmarks and local rates of change observed from 2013 state-of-the-art HEVs ${ }^{4}$

\begin{tabular}{|c|c|c|c|}
\hline Class & $\begin{array}{l}\text { State-of-the-art } \\
\text { HEV }\end{array}$ & Dominated set $^{*}$ & $\begin{array}{l}\text { Local rate } \\
\text { of change }\end{array}$ \\
\hline \multirow[t]{7}{*}{ Midsize } & 21 & $\begin{array}{l}1,3,4,5,6,7,9,10,12,13,16,18,19,21,24,27,33,38,39,43,45 \\
47,50,55,60,62,63,64,66,70,71,77,78,79,83,84,86,88,89,90, \\
91,92,97,102,104,105,106,107,111,112,113,114,115,117,118, \\
119,120,121,122,123,124,125,126,136,137,138,139,140,141\end{array}$ & 1.01562 \\
\hline & 40 & $10,40,60$ & 1.00422 \\
\hline & 56 & 38, 56, 99 & 1.00083 \\
\hline & 67 & $2,25,36,46,49,67,81,100,101,108,144,146,147$ & 1.00867 \\
\hline & 80 & $\begin{array}{l}1,2,3,4,5,6,7,9,12,13,16,18,19,24,25,27,33,36,39,43,45, \\
46,47,49,50,54,55,62,63,64,66,70,71,77,78,79,80,81,83,84, \\
86,88,89,90,91,92,97,101,102,104,105,106,107,111,112,113, \\
114,115,117,118,119,120,121,122,123,124,125,126,136,137, \\
138,139,140,141,144,146,147\end{array}$ & 1.03664 \\
\hline & 145 & $\begin{array}{l}24,25,27,30,33,39,45,46,49,50,62,64,70,71,78,79,83,84,86, \\
89,91,92,96,100,101,104,105,106,107,108,112,113,115,118, \\
119,120,121,122,123,124,125,126,137,138,139,140,141,144, \\
145,146,147\end{array}$ & 1.01961 \\
\hline & 152 & $38,68,99,152,153,154$ & 1.01367 \\
\hline \multirow[t]{2}{*}{ Large } & 61 & $30,44,58,61,76,96,103,109,148,149,150$ & N/A \\
\hline & 116 & 116,148 & N/A \\
\hline \multirow[t]{4}{*}{ SUV } & 51 & $17,20,28,31,34,51,52,69,72,87,93,95,110,128,131$ & 1.04067 \\
\hline & 58 & $\begin{array}{l}11,17,23,28,29,31,32,41,53,58,69,72,73,74,87,93,110,127, \\
128,129,131,133,134\end{array}$ & 1.03854 \\
\hline & 59 & $20,34,59$ & 1.05082 \\
\hline & 94 & $\begin{array}{l}11,15,23,28,29,32,37,41,42,48,52,53,57,65,73,74,94,95 \\
110,127,128,129,130,131,132,133,134,135,148\end{array}$ & 1.03080 \\
\hline \multirow[t]{2}{*}{ Minivan } & 26 & 8,26 & 1.03721 \\
\hline & 82 & $\begin{array}{l}1,3,4,5,6,7,9,10,11,12,13,15,16,17,18,19,20,23,29,31,32, \\
34,37,41,42,43,44,47,53,55,57,60,63,65,66,69,72,73,74,76, \\
77,82,85,87,88,90,93,97,102,109,111,114,117,127,129,130, \\
132,133,134,135,136,149,150\end{array}$ & 1.01971 \\
\hline $\begin{array}{l}\text { Pickup } \\
\text { Truck }\end{array}$ & 142 & 8,142 & 1.03721 \\
\hline
\end{tabular}

${ }^{*}$ : List of HEVs who cited the corresponding state-of-the-art HEV as a benchmark

In the midsize segment, three dominant players can be identified: Honda Accord Hybrid (21), Toyota Prius alpha (V) (80), and Infiniti M35h (145). One can further classify them such that

\footnotetext{
${ }^{4}$ Kruskal-Wallis test has been conducted to verify the non-parametric significance of differences between groups. It was shown that identified segments are non-identical populations with respect to the local rates of change (chisquared=9.8938, $\mathrm{df}=3, p$-value $=0.02964)$.
} 
Accord Hybrid as a low-end, Prius alpha (V) a middle-end, and M35h a high-end benchmark based on their MSRPs and performance characteristics.

Local rates of change of state-of-the-art HEVs indicate how much technological advancement has been observed from their dominated sets. Using the foregoing classifications, middle-end midsize HEVs have shown the fastest rate of change, i.e. 3.66\% of annual improvement for acceleration and fuel economies, whereas low-end and high-end midsize HEVs' progresses were relatively moderate, $1.56 \%$ and $1.96 \%$ respectively.

It is also interesting to note that BYD F3DM (56) and Ford C-Max Energi (152) were found to be state-of-the-art plug-in HEVs that have been competed against other plug-in HEVs listed in their dominated sets. However the technological advancement of plug-in HEV in midsize segment appeared to be modest so far possibly due to the fact that the current battery technology has been struggling with technical challenges along with cost and complexity coming from dual powertrains [26,27].

\subsection{Large segment: "emerging”}

Two large HEVs are on the 2013 state-of-the-art frontier: the BMW ActiveHybrid 7 Series (61) and the Ford C-Max Hybrid FWD (116). One may notice that these HEVs are representing two very different regions within a large HEV segment. Indeed, the BMW ActiveHybrid 7 Series, which has a 2013 equivalent MSRP of \$104,300, constitutes the most expensive HEV market segment. This is a noteworthy segment in that it is penetrating a niche of luxury market with a powerful engine and electric motor combination while still getting satisfactory MPG. In fact, the high-end automakers have finally begun to push green cars, e.g. Mercedes' S hybrid 
series or Porsche’s Panamera S series, right after Tesla proved that there is a sufficient number of upscale customers in the electric vehicle market [28].

In contrast, the Ford C-Max Hybrid FWD, which has a 2013 equivalent MSRP of \$25,200, stakes out the other end of the large segment. This unique vehicle is, in fact, targeting the niche between midsize and minivan segments to satisfy customers craving for stylish and spacious HEV but not as big as minivans [29]. Besides, the kinetic design deliberately shrinking the cargo space enables to deliver MPG of 43 which is the highest fuel economy in the large segment.

The local rates of change for the large segment could not be calculated due to their recent debut on the state-of-the-art frontier. That is, successive introductions of large HEVs could show two notable sub-segments within the frontier but the evolution of corresponding frontier facets hasn't occurred yet. Nevertheless, this emerging large HEV segment may be signaling one of the disruptive paths of future HEV development such as the recent adoption of diesel hybrid sheds light on an attempt to get a substantial boost in MPG and meet the stringent CO2 regulations at the same time [30,31].

\subsection{SUV segment: "forging ahead”}

Many industry reports point out that the SUV market is declining mostly due to the growing crossover segments as well as a low fuel economy [32]. However, at the same time, SUV is still recognized as a pure utility of a 'go anywhere' spirit that no other segment can replace in today's auto market. This motivated manufacturers to incorporate hybrid technology, especially plug-in, into the SUV market so that the hybrid SUV segment can address a market demand with the improved fuel economy [33,34]. 
The fast rates of change observed by all four state-of-the-art SUVs, Saturn Vue Hybrid (51), Audi Q5 (58), Jeep Patriot EV (59), and Porsche Cayenne S Hybrid (94), are supporting the previous argument. In particular, a relatively inexpensive SUV niche represented by Jeep Patriot $\mathrm{EV}$ and its dominated set show the fastest local rate of change of 5.08\% across all HEV segments. Furthermore, the dominant vehicles of medium and large SUVs: Audi Q5 and Cayenne S Hybrid, show local rates of change of 3.85\% and 3.08\% respectively. One may find it interesting to see how these cheap plug-in SUV and full-size luxury SUV segments would leverage the SUV market with current rate of technological advancement as opposed to the other crossover vehicles.

\subsection{Minivan segment: “crossover”}

As previously discussed, the cardinality of dominated set may imply the state-of-the-art HEV's positioning in the market. According to this, the Fit Shuttle Hybrid (82) can be regarded as a good all-round performer. Specifically, its dominated set includes all types of HEVs, which indicates that this vehicle would be one of the most representative designs across all HEV segments. However, the local rate of change of this cheap and economic minivan was found to be $1.97 \%$. This is slower than the larger minivan segment's, represented by Estima Hybrid (26), $3.72 \%$.

It should be noted here that minivans have been successful in Asia and Europe but have yet to be produced for the U.S. market. It is often pointed out that minivan's signature feature of three rows for 7 (or 8) passenger capacity would face a difficulty in the U.S. market without ensuring sufficient cargo and legroom space [35]. In addition, carmakers claim that minivans wouldn’t get much fuel economy improvement due to their big and boxy structure. Furthermore, 
minivan customers want to have not only high fuel efficiency but also long cruising ranges, which requires the optimal placement of hybrid battery packs to keep them from using up valuable space. Therefore one may have to keep in mind that current minivan segment represented by Fit Shuttle Hybrid might be valid in a specific market that values economic design, hence, not be applicable to the U.S. market nor for the expected rate of technological advancement.

\subsection{Pickup truck segment: "steady”}

There is actually only one hybrid pickup truck model (under two different brand names: Chevrolet Silverado and GMC Sierra both from General Motors) and therefore this segment reflects how much performance of this product line has advanced throughout the generations. Not surprisingly, the most recent model, Silverado 15 Hybrid 2WD (142), was found to be an state-of-the-art truck with annualized performance improvement of 3.72\%.

However, the hybrid pickup truck segment requires a cautious view on its future. The stateof-the-art hybrid truck today has fuel economy of 21 MPG and acceleration of $12.35 \mathrm{~km} / \mathrm{h} / \mathrm{s}$ with MSRP of $\$ 41,135$. One may find it unclear if this hybrid truck is more appealing than its solid gasoline version, i.e. Silverado C15 2WD with 17 MPG, acceleration of $13.70 \mathrm{~km} / \mathrm{h} / \mathrm{s}$, and $\$ 23,590$ price tag. Assuming \$5 a gallon gasoline and 20,000 miles per year, the payback period would be over 15 years. Although hybrid technology may be a good choice for other reasons, current efficiency-cost analysis suggests that the premium upfront cost for hybrid trucks is not likely offset by fuel savings. This indicates a faster rate of change through additional innovation may be needed for hybrid pickup trucks to become more prominent in the future HEV market. 


\section{Conclusion}

This study evaluates and compares the technological advancement observed in different HEV market segments over the past 15 years. The results indicate that three sub-segments exist in midsize HEVs and middle class represented by Prius alpha (V) showed the faster technological progress than other two. The performance growth as well as diversification of midsize HEVs seems to be posing a threat to two-seaters and compact segments. The overall rate of the SUV segment's technological advancement, from low price plug-in to full-size, was shown to be the fastest across the all HEV segments. The large HEVs are targeting a luxury market niche whereas minivans are showing the universal design characteristics in non U.S. markets. Finally, hybrid pickup trucks showed a steady performance upgrade however they are competing against their own solid gasoline versions to prove the utility of hybrid technologies.

The rate of technological advancement identified in each market (sub) segment can give an insight into the target setting practice for a new product development planning. That is, manufacturers may position their products within the current state-of-the-art frontier and utilize the corresponding rate of change to see whether their design targets would locate on the estimated future frontiers. One can also make use of this information on pricing strategy such that offering the similar performance as current state-of-the-art HEVs but set the reduced price using the given rate of change. This is, in fact, a strategy that was used by Nissan to boost their sales for Nissan Leaf [36].

As a future work, trade-offs between technological characteristics need to be examined so that various future technological possibilities can be estimated based on identified rate of changes. Technological forecasting for Battery Electric Vehicles (BEV) using a similar approach 
could suggest another future work with the growing interest in pure electric vehicles. The performance of BEVs is highly dependent on their battery technology. The weight of the batteries is an important factor in the energy batteries produce; batteries also incorporate a significant amount of the cost of the pure electric vehicles. In 2012, Wall Street Journal published a report in which the price of the batteries was estimated to be one third of the total price of pure electric vehicles [37]. Charging time and driving ranges are among others that are also critical for pure electric vehicles. Therefore, a solid forecasting model for BEVs requires indepth research on the battery technology to select the suitable performance metrics that would be the main indicators of performance for the different markets. 
Appendix 1 Hybrid electric vehicle dataset

\begin{tabular}{|c|c|c|c|c|c|c|c|}
\hline No. & Model & Date & $\begin{array}{c}\text { MSRP } \\
\text { (2013 equivalent) }\end{array}$ & $\begin{array}{l}\text { Acceleration } \\
\text { rate }(\mathrm{km} / \mathrm{h} / \mathrm{s})\end{array}$ & $\begin{array}{l}\text { Fuel economy } \\
\text { (MPG) }\end{array}$ & $\begin{array}{l}\text { Max of MPG } \\
\text { and MPGe } \\
\text { (MPG) }\end{array}$ & Class \\
\hline 1 & Prius(1st gen.) & 1997 & $\$ 24,509.74$ & 7.46 & 41.26 & 41.26 & $\mathrm{C}$ \\
\hline 2 & Tino Hybrid & 2000 & $\$ 35,354.97$ & 8.20 & 54.10 & 54.10 & $\mathrm{C}$ \\
\hline 3 & Prius(2nd gen.) & 2000 & $\$ 26,832.25$ & 7.97 & 45.23 & 45.23 & $\mathrm{C}$ \\
\hline 4 & Insight & 2000 & $\$ 18,936.41$ & 9.52 & 53.00 & 53.00 & TS \\
\hline 5 & Civic Hybrid 1st gen. & 2001 & $\$ 25,833.38$ & 7.04 & 47.04 & 47.04 & $\mathrm{C}$ \\
\hline 6 & Insight & 2001 & $\$ 19,036.71$ & 9.52 & 53.00 & 53.00 & TS \\
\hline 7 & Insight & 2002 & $\$ 19,137.01$ & 9.71 & 53.00 & 53.00 & TS \\
\hline 8 & Alphard Hybrid & 2003 & $\$ 38,084.77$ & 8.33 & 40.46 & 40.46 & MV \\
\hline 9 & Insight & 2003 & $\$ 19,137.01$ & 9.52 & 53.00 & 53.00 & TS \\
\hline 10 & Civic Hybrid & 2003 & $\$ 14,071.92$ & 8.62 & 41.00 & 41.00 & $\mathrm{C}$ \\
\hline 11 & Escape Hybrid & 2004 & $\$ 36,676.10$ & 10.32 & 31.99 & 31.99 & SUV \\
\hline 12 & Insight & 2004 & $\$ 19,237.31$ & 9.35 & 52.00 & 52.00 & TS \\
\hline 13 & Prius & 2004 & $\$ 20,355.64$ & 9.90 & 46.00 & 46.00 & M \\
\hline 14 & Silverado 15 Hybrid 2WD & 2004 & $\$ 30,089.64$ & 9.09 & 17.00 & 17.00 & PT \\
\hline 15 & Lexus RX400h & 2005 & $\$ 58,521.14$ & 12.76 & 28.23 & 28.23 & SUV \\
\hline 16 & Civic Hybrid 2nd gen. & 2005 & $\$ 26,354.44$ & 7.63 & 39.99 & 39.99 & $\mathrm{C}$ \\
\hline 17 & Highlander Hybrid & 2005 & $\$ 29,186.21$ & 12.76 & 29.40 & 29.40 & SUV \\
\hline 18 & Insight & 2005 & $\$ 19,387.76$ & 9.71 & 52.00 & 52.00 & TS \\
\hline 19 & Civic Hybrid & 2005 & $\$ 18,236.33$ & 8.26 & 41.00 & 41.00 & $\mathrm{C}$ \\
\hline 20 & Escape Hybrid 2WD & 2005 & $\$ 19,322.56$ & 9.52 & 29.00 & 29.00 & SUV \\
\hline 21 & Accord Hybrid & 2005 & $\$ 16,343.69$ & 14.93 & 28.00 & 28.00 & M \\
\hline 22 & Silverado 15 Hybrid 2WD & 2005 & $\$ 32,647.26$ & 11.11 & 17.00 & 17.00 & PT \\
\hline 23 & Mercury Mariner Hybrid & 2006 & $\$ 34,772.40$ & 8.98 & 32.93 & 32.93 & SUV \\
\hline 24 & Camry Hybrid & 2006 & $\$ 29,853.25$ & 11.28 & 33.64 & 33.64 & M \\
\hline 25 & Lexus GS450h & 2006 & $\$ 64,547.56$ & 18.65 & 33.40 & 33.40 & M \\
\hline 26 & Estima Hybrid & 2006 & $\$ 36,012.70$ & 9.26 & 47.04 & 47.04 & MV \\
\hline 27 & Altima Hybrid & 2006 & $\$ 29,524.75$ & 13.29 & 32.93 & 32.93 & $\mathrm{M}$ \\
\hline 28 & Chevrolet Tahoe Hybrid & 2007 & $\$ 42,924.35$ & 10.91 & 22.35 & 22.35 & SUV \\
\hline 29 & Kluger Hybrid & 2007 & $\$ 46,229.48$ & 12.76 & 25.87 & 25.87 & SUV \\
\hline 30 & Lexus LS600h/hL & 2007 & $\$ 118,543.60$ & 17.54 & 21.00 & 21.00 & M \\
\hline 31 & Tribute Hybrid & 2007 & $\$ 24,823.83$ & 11.28 & 31.75 & 31.75 & SUV \\
\hline 32 & GMC Yukon Hybrid & 2007 & $\$ 57,094.81$ & 12.28 & 21.78 & 21.78 & SUV \\
\hline 33 & Aura Hybrid & 2007 & $\$ 22,110.87$ & 10.87 & 27.00 & 27.00 & M \\
\hline 34 & Vue Hybrid & 2007 & $\$ 22,938.33$ & 10.75 & 26.00 & 26.00 & SUV \\
\hline 35 & Silverado 15 Hybrid 2WD & 2007 & $\$ 34,653.23$ & 11.49 & 17.00 & 17.00 & PT \\
\hline 36 & Crown Hybrid & 2008 & $\$ 62,290.38$ & 8.70 & 37.16 & 37.16 & M \\
\hline 37 & Cadillac Escalade Hybrid & 2008 & $\$ 78,932.81$ & 9.09 & 22.35 & 22.35 & SUV \\
\hline 38 & F3DM & 2008 & $\$ 23,744.06$ & 9.52 & 30.11 & 85.00 & M \\
\hline 39 & Altima Hybrid & 2008 & $\$ 18,675.63$ & 13.70 & 34.00 & 34.00 & M \\
\hline 40 & A5 BSG & 2009 & $\$ 11,849.43$ & 7.87 & 35.28 & 35.28 & $\mathrm{M}$ \\
\hline 41 & Lexus RX450h & 2009 & $\$ 46,233.36$ & 13.47 & 31.99 & 31.99 & SUV \\
\hline 42 & ML450 Blue HV & 2009 & $\$ 60,519.83$ & 12.60 & 23.99 & 23.99 & SUV \\
\hline 43 & Prius (3rd gen.) & 2009 & $\$ 24,641.18$ & 9.60 & 47.98 & 47.98 & $\mathrm{C}$ \\
\hline 44 & S400 Hybrid/ Hybrid Long & 2009 & $\$ 96,208.93$ & 13.89 & 26.34 & 26.34 & $\mathrm{~L}$ \\
\hline 45 & Mercury Milan Hybrid & 2009 & $\$ 30,522.57$ & 11.55 & 40.69 & 40.69 & M \\
\hline 46 & Lexus HS250h & 2009 & $\$ 38,478.15$ & 11.55 & 54.10 & 54.10 & $\mathrm{C}$ \\
\hline 47 & Avante/ Elantra LPI & 2009 & $\$ 21,872.71$ & 10.21 & 41.87 & 41.87 & $\mathrm{C}$ \\
\hline 48 & ActiveHybrid X6 & 2009 & $\$ 97,237.90$ & 17.96 & 18.82 & 18.82 & SUV \\
\hline 49 & SAI & 2009 & $\$ 39,172.44$ & 11.55 & 54.10 & 54.10 & $\mathrm{M}$ \\
\hline 50 & Malibu Hybrid & 2009 & $\$ 24,768.79$ & 9.09 & 29.00 & 29.00 & $\mathrm{M}$ \\
\hline 51 & Vue Hybrid & 2009 & $\$ 26,408.67$ & 13.70 & 28.00 & 28.00 & SUV \\
\hline 52 & Aspen HEV & 2009 & $\$ 44,903.77$ & 13.51 & 21.00 & 21.00 & SUV \\
\hline 53 & Durango & 2009 & $\$ 41,033.24$ & 8.33 & 21.00 & 21.00 & SUV \\
\hline 54 & Auris HSD & 2010 & $\$ 35,787.29$ & 8.85 & 68.21 & 68.21 & C \\
\hline
\end{tabular}




\begin{tabular}{|c|c|c|c|c|c|c|c|}
\hline 55 & CR-Z & 2010 & $\$ 21,435.54$ & 9.24 & 37.00 & 37.00 & TS \\
\hline 56 & F3DM PHEV & 2010 & $\$ 23,124.59$ & 9.24 & 30.15 & 85.00 & M \\
\hline 57 & Touareg HV & 2010 & $\$ 64,198.95$ & 15.38 & 28.70 & 28.70 & SUV \\
\hline 58 & Audi Q5 & 2010 & $\$ 37,510.86$ & 14.08 & 33.64 & 33.64 & SUV \\
\hline 59 & Jeep Patriot EV & 2010 & $\$ 17,045.06$ & 12.05 & 29.40 & 38.00 & SUV \\
\hline 60 & Besturn B50 & 2010 & $\$ 14,586.61$ & 7.14 & 31.28 & 31.28 & M \\
\hline 61 & ActiveHybrid 7 Series & 2010 & $\$ 104,300.43$ & 20.41 & 22.11 & 22.11 & $\mathrm{~L}$ \\
\hline 62 & Lincoln MKZ Hybrid & 2010 & $\$ 37,036.64$ & 11.15 & 37.63 & 37.63 & M \\
\hline 63 & Fit/ Jazz Hybrid & 2010 & $\$ 16,911.85$ & 8.26 & 30.00 & 30.00 & $\mathrm{C}$ \\
\hline 64 & Sonata HV & 2010 & $\$ 28,287.66$ & 14.70 & 37.00 & 37.00 & M \\
\hline 65 & Cayenne S HV & 2010 & $\$ 73,183.47$ & 14.71 & 26.11 & 26.11 & SUV \\
\hline 66 & Insight & 2010 & $\$ 19,859.16$ & 9.17 & 41.00 & 41.00 & $\mathrm{C}$ \\
\hline 67 & Fuga Hybrid/ Infiniti M35h & 2010 & $\$ 70,157.02$ & 18.65 & 33.64 & 33.64 & M \\
\hline 68 & Chevrolet Volt & 2010 & $\$ 42,924.35$ & 10.78 & 35.00 & 93.00 & $\mathrm{C}$ \\
\hline 69 & Tribute Hybrid 4WD & 2010 & $\$ 27,968.32$ & 12.35 & 29.00 & 29.00 & SUV \\
\hline 70 & Fusion Hybrid FWD & 2010 & $\$ 28,033.51$ & 11.49 & 39.00 & 39.00 & M \\
\hline 71 & HS $250 \mathrm{~h}$ & 2010 & $\$ 34,753.53$ & 11.76 & 35.00 & 35.00 & $\mathrm{C}$ \\
\hline 72 & Mariner Hybrid FWD & 2010 & $\$ 30,194.95$ & 11.63 & 32.00 & 32.00 & SUV \\
\hline 73 & RX 450h & 2010 & $\$ 42,812.54$ & 13.89 & 30.00 & 30.00 & SUV \\
\hline 74 & ML450 Hybrid 4natic & 2010 & $\$ 55,164.33$ & 12.99 & 22.00 & 22.00 & SUV \\
\hline 75 & Silverado 15 Hybrid 2WD & 2010 & $\$ 38,454.56$ & 11.76 & 22.00 & 22.00 & $\mathrm{PT}$ \\
\hline 76 & S400 Hybrid & 2010 & $\$ 88,212.78$ & 12.99 & 21.00 & 21.00 & $\mathrm{~L}$ \\
\hline 77 & Aqua & 2011 & $\$ 22,850.87$ & 9.35 & 50.00 & 50.00 & $\mathrm{C}$ \\
\hline 78 & Lexus CT200h & 2011 & $\$ 30,082.16$ & 9.71 & 42.00 & 42.00 & $\mathrm{C}$ \\
\hline 79 & Civic Hybrid 3rd gen & 2011 & $\$ 24,999.59$ & 9.60 & 44.36 & 44.36 & $\mathrm{C}$ \\
\hline 80 & Prius alpha(v) & 2011 & $\$ 30,588.35$ & 10.00 & 72.92 & 72.92 & M \\
\hline 81 & 3008 Hybrid4 & 2011 & $\$ 45,101.54$ & 11.36 & 61.16 & 61.16 & $\mathrm{C}$ \\
\hline 82 & Fit Shuttle Hybrid & 2011 & $\$ 16,394.36$ & 7.52 & 58.80 & 58.80 & MV \\
\hline 83 & Buick Regal eAssist & 2011 & $\$ 27,948.93$ & 12.05 & 25.99 & 25.99 & M \\
\hline 84 & Prius v & 2011 & $\$ 27,272.28$ & 9.51 & 32.93 & 32.93 & M \\
\hline 85 & Freed/ Freed Spike Hybrid & 2011 & $\$ 27,972.07$ & 6.29 & 50.81 & 50.81 & MV \\
\hline 86 & Optima K5 HV & 2011 & $\$ 26,549.16$ & 10.54 & 36.00 & 36.00 & M \\
\hline 87 & Escape Hybrid FWD & 2011 & $\$ 30,661.34$ & 12.35 & 32.00 & 32.00 & SUV \\
\hline 88 & Insight & 2011 & $\$ 18,254.38$ & 9.52 & 41.00 & 41.00 & $\mathrm{C}$ \\
\hline 89 & MKZ Hybrid FWD & 2011 & $\$ 34,748.52$ & 11.49 & 39.00 & 39.00 & M \\
\hline 90 & CR-Z & 2011 & $\$ 19,402.80$ & 12.20 & 37.00 & 37.00 & TS \\
\hline 91 & Sonata Hybrid & 2011 & $\$ 25,872.07$ & 11.90 & 36.00 & 36.00 & M \\
\hline 92 & Camry Hybrid & 2011 & $\$ 27,130.82$ & 13.89 & 33.00 & 33.00 & M \\
\hline 93 & Tribute Hybrid 2WD & 2011 & $\$ 26,213.09$ & 12.50 & 32.00 & 32.00 & SUV \\
\hline 94 & Cayenne S Hybrid & 2011 & $\$ 67,902.28$ & 18.52 & 21.00 & 21.00 & SUV \\
\hline 95 & Touareg Hybrid & 2011 & $\$ 50,149.39$ & 16.13 & 21.00 & 21.00 & SUV \\
\hline 96 & ActiveHybrid 7i & 2011 & $\$ 102,605.66$ & 18.18 & 20.00 & 20.00 & $\mathrm{M}$ \\
\hline 97 & Prius c & 2012 & $\$ 19,006.62$ & 9.35 & 50.00 & 50.00 & $\mathrm{C}$ \\
\hline 98 & Prius PHV & 2012 & $\$ 32,095.61$ & 8.82 & 50.00 & 95.00 & M \\
\hline 99 & Ampera & 2012 & $\$ 31,739.55$ & 11.11 & 37.00 & 98.00 & $\mathrm{C}$ \\
\hline 100 & ActiveHybrid 5 Series & 2012 & $\$ 62,180.23$ & 16.67 & 26.00 & 26.00 & M \\
\hline 101 & Lexus GS450h & 2012 & $\$ 59,126.14$ & 16.95 & 31.00 & 31.00 & M \\
\hline 102 & Insight & 2012 & $\$ 18,555.28$ & 9.42 & 42.00 & 42.00 & $\mathrm{C}$ \\
\hline 103 & Chevrolet Volt & 2012 & $\$ 39,261.96$ & 11.11 & 37.00 & 94.00 & $\mathrm{C}$ \\
\hline 104 & Camry Hybrid LE & 2012 & $\$ 26,067.66$ & 13.16 & 41.00 & 41.00 & M \\
\hline 105 & MKZ Hybrid FWD & 2012 & $\$ 34,858.84$ & 11.49 & 39.00 & 39.00 & M \\
\hline 106 & M35h & 2012 & $\$ 53,860.45$ & 19.23 & 29.00 & 29.00 & M \\
\hline 107 & LaCrosse eAssist & 2012 & $\$ 30,049.52$ & 11.36 & 29.00 & 29.00 & M \\
\hline 108 & ActiveHybrid 5 Series & 2012 & $\$ 61,132.11$ & 17.54 & 26.00 & 26.00 & M \\
\hline 109 & Panamera S Hybrid & 2012 & $\$ 95,283.85$ & 17.54 & 25.00 & 25.00 & $\mathrm{~L}$ \\
\hline 110 & Yukon 1500 Hybrid 2WD & 2012 & $\$ 52,626.77$ & 13.50 & 21.00 & 21.00 & SUV \\
\hline 111 & Prius C & 2013 & $\$ 19,080.00$ & 8.70 & 50.00 & 50.00 & $\mathrm{C}$ \\
\hline 112 & Jetta Hybrid & 2013 & $\$ 24,995.00$ & 12.66 & 45.00 & 45.00 & $\mathrm{C}$ \\
\hline 113 & Civic Hybrid & 2013 & $\$ 24,360.00$ & 10.20 & 44.00 & 44.00 & $\mathrm{C}$ \\
\hline 114 & Prius & 2013 & $\$ 24,200.00$ & 10.20 & 50.00 & 50.00 & M \\
\hline 115 & Fusion Hybrid FWD & 2013 & $\$ 27,200.00$ & 11.72 & 47.00 & 47.00 & M \\
\hline 116 & C-Max Hybrid FWD & 2013 & $\$ 25,200.00$ & 12.35 & 43.00 & 43.00 & $\mathrm{~L}$ \\
\hline
\end{tabular}




\begin{tabular}{|c|c|c|c|c|c|c|c|}
\hline 117 & Insight & 2013 & $\$ 18,600.00$ & 11.76 & 42.00 & 42.00 & $\mathrm{C}$ \\
\hline 118 & Camry Hybrid LE & 2013 & $\$ 26,140.00$ & 13.51 & 41.00 & 41.00 & $\mathrm{M}$ \\
\hline 119 & Camry Hybrid LXLE & 2013 & $\$ 27,670.00$ & 13.33 & 40.00 & 40.00 & M \\
\hline 120 & Sonata Hybrid & 2013 & $\$ 25,650.00$ & 11.76 & 38.00 & 38.00 & M \\
\hline 121 & Optima Hybrid & 2013 & $\$ 25,900.00$ & 11.63 & 38.00 & 38.00 & M \\
\hline 122 & Sonata Hybrid Limited & 2013 & $\$ 30,550.00$ & 11.76 & 37.00 & 37.00 & $\mathrm{M}$ \\
\hline 123 & Optima Hybrid EX & 2013 & $\$ 31,950.00$ & 11.36 & 37.00 & 37.00 & $\mathrm{M}$ \\
\hline 124 & Malibu eAssist & 2013 & $\$ 24,985.00$ & 11.49 & 29.00 & 29.00 & M \\
\hline 125 & LaCrosse eAssist & 2013 & $\$ 31,660.00$ & 11.36 & 29.00 & 29.00 & M \\
\hline 126 & Regal eAssist & 2013 & $\$ 29,015.00$ & 12.20 & 29.00 & 29.00 & M \\
\hline 127 & RX 450h & 2013 & $\$ 46,310.00$ & 12.99 & 30.00 & 30.00 & SUV \\
\hline 128 & Highlander Hybrid 4WD & 2013 & $\$ 40,170.00$ & 13.89 & 28.00 & 28.00 & SUV \\
\hline 129 & Q5 Hybrid & 2013 & $\$ 50,900.00$ & 14.71 & 26.00 & 26.00 & SUV \\
\hline 130 & Cayenne S Hybrid & 2013 & $\$ 69,850.00$ & 16.39 & 21.00 & 21.00 & SUV \\
\hline 131 & Touareg Hybrid & 2013 & $\$ 62,575.00$ & 16.13 & 21.00 & 21.00 & SUV \\
\hline 132 & Escalade Hybrid 2WD & 2013 & $\$ 74,425.00$ & 11.63 & 21.00 & 21.00 & SUV \\
\hline 133 & Tahoe Hybrid 2WD & 2013 & $\$ 53,620.00$ & 11.90 & 21.00 & 21.00 & SUV \\
\hline 134 & Yukon 1500 Hybrid 2WD & 2013 & $\$ 54,145.00$ & 11.88 & 21.00 & 21.00 & SUV \\
\hline 135 & Yukon 1500 Hybrid 4WD & 2013 & $\$ 61,960.00$ & 13.33 & 21.00 & 21.00 & SUV \\
\hline 136 & CR-Z & 2013 & $\$ 19,975.00$ & 11.11 & 37.00 & 37.00 & TS \\
\hline 137 & MKZ Hybrid FWD & 2013 & $\$ 35,925.00$ & 14.03 & 45.00 & 45.00 & M \\
\hline 138 & CT 200h & 2013 & $\$ 32,050.00$ & 10.31 & 42.00 & 42.00 & $\mathrm{C}$ \\
\hline 139 & ES 300h & 2013 & $\$ 39,250.00$ & 12.35 & 40.00 & 40.00 & M \\
\hline 140 & ILX Hybrid & 2013 & $\$ 28,900.00$ & 9.26 & 38.00 & 38.00 & $\mathrm{C}$ \\
\hline 141 & ActiveHybrid 3 & 2013 & $\$ 49,650.00$ & 14.93 & 28.00 & 28.00 & $\mathrm{C}$ \\
\hline 142 & Silverado 15 Hybrid 2WD & 2013 & $\$ 41,135.00$ & 12.35 & 21.00 & 21.00 & PT \\
\hline 143 & Sierra 15 Hybrid 2WD & 2013 & $\$ 41,555.00$ & 10.00 & 21.00 & 21.00 & PT \\
\hline 144 & GS 450h & 2013 & $\$ 59,450.00$ & 16.67 & 31.00 & 31.00 & M \\
\hline 145 & M35h & 2013 & $\$ 54,750.00$ & 19.61 & 29.00 & 29.00 & $\mathrm{M}$ \\
\hline 146 & E400 Hybrid & 2013 & $\$ 55,800.00$ & 14.93 & 26.00 & 26.00 & $\mathrm{M}$ \\
\hline 147 & ActiveHybrid 5 Series & 2013 & $\$ 61,400.00$ & 12.99 & 26.00 & 26.00 & $\mathrm{M}$ \\
\hline 148 & ActiveHybrid 7L & 2013 & $\$ 84,300.00$ & 18.18 & 25.00 & 25.00 & $\mathrm{~L}$ \\
\hline 149 & Panamera S Hybrid & 2013 & $\$ 96,150.00$ & 18.52 & 25.00 & 25.00 & $\mathrm{~L}$ \\
\hline 150 & S400 Hybrid & 2013 & $\$ 92,350.00$ & 13.89 & 21.00 & 21.00 & $\mathrm{~L}$ \\
\hline 151 & Prius Plug-in Hybrid & 2013 & $\$ 32,000.00$ & 9.17 & 50.00 & 95.00 & M \\
\hline 152 & C-Max Energi Plug-in Hybrid & 2013 & $\$ 32,950.00$ & 11.76 & 43.00 & 100.00 & M \\
\hline 153 & Fusion Energi Plug-in Hybrid & 2013 & $\$ 38,700.00$ & 11.76 & 43.00 & 100.00 & M \\
\hline 154 & Chevrolet Volt & 2013 & $\$ 39,145.00$ & 11.11 & 37.00 & 98.00 & $\mathrm{C}$ \\
\hline
\end{tabular}


Appendix 22013 state-of-the-art frontiers of different HEV segments
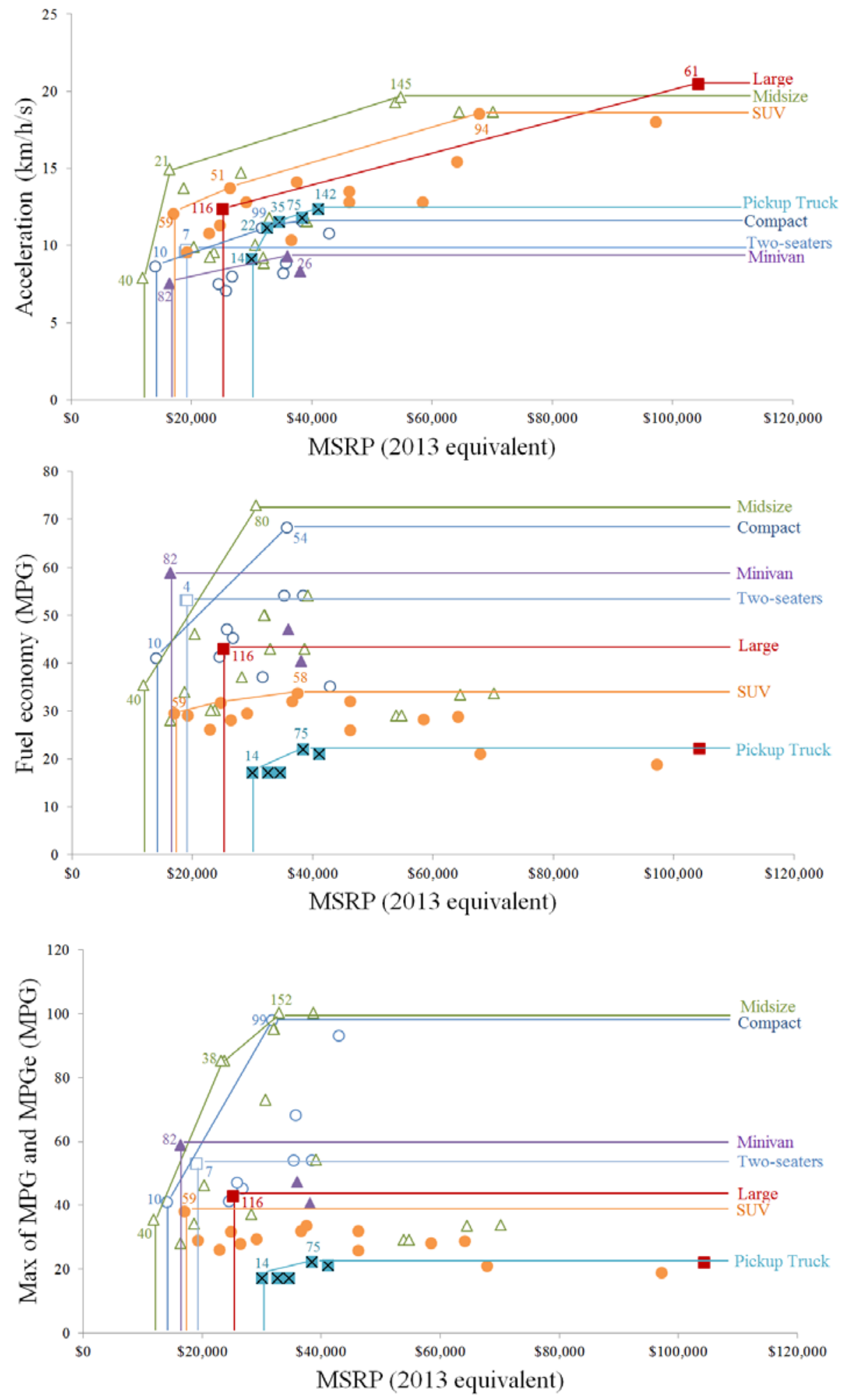

$\square$ Two-seaters $\bigcirc$ Compact $\triangle$ Midsize $\square$ Large $\odot$ SUV $\Delta$ Minivan $\quad$ Pickup Truck 


\section{References}

[1] S.R. Jahromi, A.A. Tudori, T.R. Anderson, Forecasting hybrid electric vehicles using TFDEA, in: Technol. Manag. IT-Driven Serv., PICMET, San Jose, 2013: pp. 2098-2107.

[2] A.A. Tudorie, Technology forecasting of electric vehicles using data envelopment analysis, Delft University of Technology, 2012.

[3] D.-J. Lim, N. Runde, T.R. Anderson, Applying Technology Forecasting to New Product Development Target Setting of LCD Panels, in: R. Klimberg, K.D. Lawrence (Eds.), Adv. Bus. Manag. Forecast., 9th ed., Emerald Group Publishing Limited, 2013: p. 340.

[4] D.-J. Lim, T.R. Anderson, J. Kim, Forecast of wireless communication technology: A comparative study of regression and TFDEA Model, in: Technol. Manag. Emerg. Technol. (PICMET), 2012 Proc. PICMET ’12, PICMET, Vancouver, Canada, 2012.

[5] O.L. Inman, Technology forecasting using data envelopment analysis, Portland State University, 2004.

[6] O. Inman, T.R. Anderson, R. Harmon, Predicting U.S. jet fighter aircraft introductions from 1944 to 1982: A dogfight between regression and TFDEA, Technol. Forecast. Soc. Change. 73 (2006) 1178-1187.

[7] T.R. Anderson, R. Fare, S. Grosskopf, L. Inman, X. Song, Further examination of Moore's law with data envelopment analysis, Technol. Forecast. Soc. Change. 69 (2002) 465-477.

[8] A.-M. Lamb, T.R. Anderson, T. Daim, Research and development target-setting difficulties addressed through the emergent method: technology forecasting using data envelopment analysis, R\&D Manag. 42 (2012) 327-341.

[9] T.R. Anderson, T.U. Daim, J. Kim, Technology forecasting for wireless communication, Technovation. 28 (2008) 602-614.

[10] B.F. Cole, An evolutionary method for synthesizing technological planning and architectural advance, Georgia Institute of Technology, 2009.

[11] H.O. Fried, C.A.K. Lovell, S.S. Schmidt, The measurement of productive efficiency and productivity growth, 1st ed., Oxford University Press, New York, 2008.

[12] D.-J. Lim, T.R. Anderson, Improving Forecast Accuracy by a Segmented Rate of Change in Technology Forecasting using Data Envelopment Analysis, Submitted. (2013). 
[13] T.R. Anderson, L. Inman, Resolving the issue of multiple optima in Technology Forecasting using Data Envelopment Analysis, Technol. Manag. Energy Smart World (PICMET), 2011 Proc. PICMET '11. (2011) 1-5.

[14] D.-J. Lim, T.R. Anderson, O. Inman, Choosing Effective Dates from Multiple Optima in Technology Forecasting using Data Envelopment Analysis (TFDEA), Technol. Forecast. Soc. Change. (2014) In press.

[15] J. Ruggiero, On the measurement of technical efficiency in the public sector, Eur. J. Oper. Res. 90 (1996) 553-565.

[16] R.D. Banker, R.C. Morey, Use of Categorical Variables in Data Envelopment Analysis, Manage. Sci. 32 (1986) 1613-1627.

[17] OANDA Corporation, OANDA Currency Converter, (2013).

[18] M.J. Boskin, E.R. Dulberger, R.J. Gordon, Z. Griliches, D.W. Jorgenson, Consumer Prices, the Consumer Price Index, and the Cost of Living, J. Econ. Perspect. 12 (1998) 326.

[19] Environmental Protection Agency (EPA), The Official U.S. Government Source for Fuel Economy Information, (2013).

[20] Electric and Hybrid Vehicle Research, Development, and Demonstration Program; Petroleum-Equivalent Fuel Economy Calculation, (2000).

[21] D.-J. Lim, T.R. Anderson, An introduction to Technology Forecasting with a TFDEA Excel add-in, in: Technol. Manag. Emerg. Technol. (PICMET), 2012 Proc. PICMET '12, 2012.

[22] E.A. Sanchez, Toyota Targeting Higher Efficiency with Next Generation Prius, Automot. News. (2013).

[23] Toyota, Toyota’s Medium to Long Term Growth Initiatives, Toyota Annu. Rep. (2012).

[24] CarsDirect, Hybrid Car Buying Guide, (2013).

[25] J.R. Doyle, R.H. Green, Comparing products using data envelopment analysis, Omega. 19 (1991) 631-8.

[26] U.S. Department of Energy, Discussion Meeting on Plug-In Hybrid Electric Vehicles, Washington, DC, 2006.

[27] S.S.S. Shao, M. Pipattanasomporn, S. Rahman, Challenges of PHEV penetration to the residential distribution network, 2009 IEEE Power Energy Soc. Gen. Meet. (2009). 
[28] J. Garthwaite, Tesla Motors' Success Gives Electric Car Market a Charge, Natl. Geogr. Mag. (2013).

[29] J. Voelcker, 2013 Ford C-Max - Review, Car Connect. (2013).

[30] T. Hazeldine, S. Kollamthodi, C. Brannigan, M. Morris, L. Deller, Market Outlook to 2022 for Battery Electric and Plug-in Hybrid Electric Vehicles, 2009.

[31] J. Borras, LA 2013: Volkswagen Announces 256 MPG Diesel Hybrid, GAS2. (2013).

[32] J. Siu, Top 10 Cheapest SUVs, AutoGuide. (2013).

[33] M. Duvall, Comparing the Benefits and Impacts of Hybrid Electric Vehicle Options for Compact Sedan and Sport Utility Vehicles, 2002.

[34] D.L. Greene, K.G. Duleep, W.S. McManus, Future potential of hybrid and diesel powertrains in the US light-duty vehicle market., Oak Ridge Natl. Lab. (2004) 1-77.

[35] J. Young, Getting Small with Hybrid Mini Vans, 1st Hybrid. (2013).

[36] J. Hirsch, Nissan Leaf: Carmaker drops price, raises range of Japanese model, Los Angeles Times. (2012).

[37] M. Ramsey, Ford CEO: Battery is Third of Electric Car Cost, Wall Str. J. (2012). 